\title{
PRÁTICAS PEDAGÓGICAS INCLUSIVAS E PROCESSOS DE APROPRIAÇÃO DA LINGUAGEM ESCRITA
}

\author{
Ana Paula de Freitas \\ Débora Dainez \\ Claudia Adriana Silva de Mello Carvalho
}

\begin{abstract}
Resumo
Este artigo aborda a temática das práticas pedagógicas alfabetizadoras e inclusivas e visa investigar o processo de apropriação da linguagem escrita e as possibilidades de desenvolvimento de um aluno com hipótese diagnóstica de deficiência intelectual matriculado no segundo ano do ensino fundamental da educação básica. Fundamenta-se teórica e metodologicamente na perspectiva histórico-cultural. As análises das situações de sala de aula permitem argumentar que as práticas alfabetizadoras integram a situação social de desenvolvimento, possibilitando a constituição de novas formações psíquicas. Considera-se que as propostas de ensino da linguagem escrita devem priorizar as crianças e suas vivências, as múltiplas relações que ela estabelece com a linguagem e as situações enunciativas que englobam os aspectos formais e a produção de sentidos.
\end{abstract}

Palavras-chave: teoria histórico-cultural; linguagem escrita; educação especial.

\section{INCLUSIVE PEDAGOGICAL PRACTICES AND PROCESSES OF APPROPRIATION OF WRITTEN LANGUAGE}

\begin{abstract}
This article addresses the subject of literacy and inclusive pedagogical practices and investigates the process of appropriation of written language and the possibilities of development of a student with the diagnostic hypothesis of intellectual disability enrolled in the second year of elementary school. It is theoretically and methodologically based on the cultural-historical perspective. The analysis of classroom situations allows us to argue that literacy practices integrate the social situation of development, enabling the constitution of new psychic formations. It is considered that the teaching proposals of written language should prioritize children and their experiences, the multiple relationships it establishes with language, and enunciative situations that encompass formal aspects and the production of meanings.
\end{abstract}

Keywords: cultural-historical theory; written language; special education.

\section{PRÁCTICAS PEDAGÓGICAS INCLUSIVAS Y PROCESOS DE APROPIACIÓN DEL LENGUAJE ESCRITO}

Resumen

Este artículo aborda la temática de la alfabetización y las prácticas pedagógicas inclusivas y tiene como objetivo investigar el proceso de apropiación del lenguaje escrito y las posibilidades de desarrollo de un alumno con hipótesis diagnóstica de discapacidad intelectual matriculado en el segundo año de educación básica en educación básica. Se basa teórica y metodológicamente en la perspectiva histórico-cultural. El análisis de las situaciones del aula permite argumentar que las prácticas de alfabetización integran la situación social del desarrollo, posibilitando la constitución de nuevas formaciones psíquicas. Se considera que las propuestas didácticas del lenguaje escrito deben priorizar a los niños y sus vivencias, las múltiples relaciones 
que establece con el lenguaje y las situaciones enunciativas que engloban los aspectos formales y la producción de significados.

Palabras clave: teoría histórico-cultural; lengua escrita; educación especial.

\section{INTRODUÇÃO}

No período em que esteve em pauta no país a elaboração da política educacional pública sob a ótica da inclusão e da afirmação da educação como direito social, podemos acompanhar uma ampliação significativa do acesso de alunos com deficiência na rede regular de ensino (MELETTI, BUENO, 2011; CASTRO, DALL'ACQUA, 2013).

A presença desses estudantes nas escolas regulares foi fundamental para colocá-los na agenda de discussão das políticas educacionais e tensionar ações com vistas à promoção de práticas pedagógicas inclusivas no espaço da sala de aula comum. Há esforços no sentido de sustentar a permanência escolar desse público com ênfase no ensino e aprendizagem. Todavia, são muitos os entraves enfrentados no cotidiano escolar para que o processo de escolarização aconteça de maneira satisfatória.

Estudos de Carvalho (2013); Pletsch (2014); Souza (2018); Freitas, Pinto, Monteiro (2019); Dainez, Smolka (2019) focalizam os meandros das práticas pedagógicas e evidenciam o pressuposto da incapacidade e a centralidade do laudo permeando as relações de ensino. As especificidades educacionais são diluídas ou correlatas às deficiências. Deflagra-se o desafio da mediação pedagógica em assegurar a apropriação do conhecimento escolar aos alunos com deficiência em um contexto educacional marcado pelas desigualdades estruturais que caracterizam o processo social (PADILHA, OLIVEIRA, 2013; DAINEZ, FREITAS, 2018).

O modelo de escola vigente reflete uma sociedade capacitista e hierarquizada economicamente, que demanda distribuição seletiva e fragmentada do conhecimento e prioriza a aquisição de competências e habilidades, tendo como base a homogeneidade dos processos de ensino e aprendizagem. Como nos ajudam a pensar Marsiglia e Saviani (2017, p. 12), quanto mais a escola "[...] esfacela os conteúdos e desqualifica o papel da educação na humanização dos seres humanos, mas ela garante o sobreviver e não o viver". Com efeito, as (im)possibilidades de ensinoaprendizagem não são determinadas pelos aspectos orgânicos e genéticos intrínsecos ao indivíduo, mas estão relacionadas aos fatores históricos, culturais e sociais que operam na organização do trabalho pedagógico na sua totalidade.

De acordo com Saviani (2009, 2013), a escola condensa o conflito de interesses que caracteriza a sociedade de classes. Há, portanto, nesse espaço, disputa por diferentes projetos de educação e sociedade. Isso significa que é dentro da escola, intervindo no miúdo das relações de ensino, que se sustenta a luta pelo direito ao conhecimento sistematizado que têm todas as crianças, com ou sem deficiência. Se por um lado, a escola reproduz em sua lógica organizacional a exclusão social, por outro, a escolarização, entendida como um processo intencional, planejado e mediado, tem como objetivo o desenvolvimento humano.

A discussão sobre a configuração de práticas pedagógicas inclusivas associada a garantia do direito dos estudantes com deficiência ao ensino-aprendizagem nos conduz para a questão da alfabetização. Com ancoragem na teoria histórico-cultural do desenvolvimento humano e em diálogo com as ideias de Saviani (2013), assumimos o pressuposto de que o ser humano é constituído socialmente e de que a escola, enquanto instituição historicamente comprometida com a apropriação do conhecimento sistematizado, é o local de novas aprendizagens e desenvolvimento cultural da personalidade. Entendemos que a apropriação da linguagem escrita, uma das mais 
importantes produções sociais, é primazia para o acesso à cultura letrada e aos conhecimentos sistematizados, os quais representam a síntese da história de desenvolvimento da atividade humana.

Com base nesses pressupostos, temos como objetivo investigar práticas pedagógicas alfabetizadoras e inclusivas, focalizando o processo de apropriação da linguagem escrita e as possibilidades de desenvolvimento de um aluno com hipótese diagnóstica de deficiência intelectual matriculado no segundo ano do ensino fundamental da educação básica. Ao priorizarmos a relação da criança com deficiência com a escrita no contexto escolar, indagamos sobre o que as práticas alfabetizadoras e inclusivas potencializam como situação social de desenvolvimento na constituição de novas formações psíquicas.

\section{A FUNÇÃO DA ESCRITA NO DESENVOLVIMENTO DO PSIQUISMO HUMANO: PREMISSAS TEÓRICO-METODOLÓGICAS}

Ao teorizar sobre a gênese social das funções psíquicas, Vigotski (1995) concebe a linguagem como atividade simbólica, mediadora das relações entre as pessoas, dos processos comunicacionais e da produção/apropriação do conhecimento, e como prática social constitutiva dos processos de desenvolvimento humano. Nesta ótica, a escrita é uma forma de linguagem, organizada a partir de um sistema simbólico extremamente complexo, que subsidia novas formações e relações interfuncionais.

A apropriação da linguagem escrita é entendida como parte da cultura humana, quer dizer da incorporação dos meios elaborados e estruturados na sociogênese do desenvolvimento. Neste sentido, Vigotski (1995) e Luria (2006) referem-se a uma pré-história da escrita. A aquisição dessa atividade pela criança traz implicada a conquista de processos e técnicas situados na história de produção humana e subsidia novas possibilidades de desenvolvimento futuro.

Para que a criança se aproprie da linguagem escrita, aprenda o conceito, a função e a técnica da escrita, é necessário um longo e complexo caminho, processual e dinâmico. Os processos pelos quais passam uma criança no percurso de sua aquisição, iniciam-se a partir do gesto, primeiro signo visual que contém a futura escrita, passam pelo simbolismo do desenho, da brincadeira, até alcançar a simbolização da escrita.

Em um primeiro momento, ao desenhar, as crianças inicialmente representam seus gestos no papel, de modo que seus traços são a materialização desses gestos. O desenho é um precursor da escrita, pois no decorrer do desenvolvimento, a criança se expressa pelos desenhos. Há um segundo momento de ligação entre o gesto e a escrita, que é representado pela brincadeira de fazde-conta, na qual a criança atribui significado aos objetos. A brincadeira está plena de gestos indicadores; um objeto pode fazer a função de outro, desde que permita seus gestos. Para Vigotski (1995), a representação simbólica do jogo constitui-se como uma forma singular de linguagem que conduz à linguagem escrita.

O autor nos chama, assim, a atenção para o fato de que antes mesmo de começar a escrever, a criança lida com a dimensão simbólica da linguagem escrita. Trata-se de um simbolismo manifestado por meio de gestos, garatujas e desenhos. A escrita propriamente dita ocorre quando a criança compreende que o que se pode "desenhar" não são os objetos, mas a linguagem. Ressaltase que em sua complexa trajetória, a linguagem escrita configura-se como uma imensa conquista para a entrada da criança no universo cultural.

Com base nas discussões de Vigotski (1996) sobre a periodização do desenvolvimento e sua relação com o ensino, podemos, ainda, abordar a escrita como nova formação psíquica, socialmente 
construída e impregnada da historicidade humana, que compõe a integralidade do desenvolvimento cultural da personalidade. O autor define o conceito de nova formação como:

[...] el nuevo tipo de estructura de la personalidad y de su actividad, los cambios psíquicos y sociales que se producen por primera vez en cada edad y determinan, en el aspecto más importante y fundamental, la consciencia del niño, su relación con el medio, su vida interna y externa, todo el curso de su desarrollo en el período dado (VIGOTSKI, 1996, p. 254-255).

As mudanças das formas de atividade psíquica, ou seja, as novas formações que emergem no processo de desenvolvimento dependem da orientação do meio social. Assim sendo, a manifestação e o transcurso da periodização devem ser examinados a partir da análise das situações sociais de desenvolvimento, que implicam considerar as demandas que se colocam em cada etapa da vida social, as expectativas e objetivos propostos, os modos pelos quais eles são cobrados, exigidos.

La situación social del desarrollo es el punto de partida para todos los cambios dinámicos que se producen en el desarrollo durante el período de cada edad. Determina plenamente y por entero las formas y la trayectoria que permiten al niño adquirir nuevas propriedades de la personalidad, ya que la realidad social es la verdadera fuente del desarrollo, la posibilidad de que lo social se transforme en individual (VIGOTSKI, 1996, p. 264).

As novas formações psíquicas, produzidas no curso dos diferentes períodos, condizem com a situação social de desenvolvimento da criança. Dessa forma, as particularidades que constituem a personalidade não são determinadas biologicamente, mas assumem caráter social. Isso significa dizer que a condição orgânica não é impeditiva de novas formações psíquicas, uma vez que é na relação com a sociedade que o ser humano desenvolve processos e características resultantes do desenvolvimento metódico de toda a humanidade (VIGOTSKI, 1997, 2018).

Neste sentido, Vigotski (2018, p. 85) afirma que “[...] no desenvolvimento da criança, o que deve ser obtido ao final, como seu resultado, é dado, desde início, pelo meio". O meio social é tomado como fonte de desenvolvimento de novas formações psíquicas. As particularidades do meio direcionam a constituição das particularidades da personalidade da criança. Centraliza-se nesse postulado a relação criança-meio, em que "[...] não é apenas a criança que muda, mas também a sua relação com o meio, que começa a influenciá-la de uma nova maneira" (VIGOTSKI, 2018, p. 83).

Ao discutir sobre o conceito de vivência enquanto unidade de análise da relação criançameio, Vigotski (2018, p. 77) assinala a importância de se compreender como a criança vivencia determinada situação social. Ou melhor, como, pela via da linguagem, ela seleciona elementos do meio e os referenciam a experiências já vividas, atribuindo sentido e generalizando determinado acontecimento enunciativo-discursivo. Desse modo, ter a criança alfabetizada como valor, implica privilegiar, no curso singular do processo de desenvolvimento, as vivências da relação dessa com a escrita, compreendendo os seus modos de conhecer, de aprender, de significar, seus interesses, abrindo possibilidades para novos interesses, novas atividades, novas significações.

A linguagem escrita está, portanto, intrinsecamente vinculada às dinâmicas sociais nas quais as crianças estão inseridas e promove mudanças nas situações sociais de desenvolvimento, sustentando novas formações.

Essa discussão nos leva a pensar na organização do meio escolar. Como criar situações sociais de desenvolvimento da linguagem escrita na escola, a fim de ampliar as possibilidades de 
apropriação da cultura pelas crianças (com deficiência)? Visto que toda forma de linguagem é mediada socialmente, ou seja, constituída na relação com outro e implica um "[...] laborioso trabalho simbólico" (SMOLKA, 2019, p. 19), os modos de ensinar e os modos de aprender se entretecem no processo de alfabetização e, para além dos aspectos técnicos envolvidos na codificação e decodificação, o ensino-aprendizagem da escrita requer imersão da criança nas práticas sociais, produção de sentidos e envolvimento afetivo-cognitivo em atividades significativas.

Assumir a sociogênese do desenvolvimento humano e a dimensão simbólica da linguagem (VIGOTSKI, 1995, 1996), nos leva, portanto, a discutir a alfabetização, mediante a qual se alcança a aprendizagem da escrita, como condição de acesso à cultura letrada e ao conhecimento sistematizado, ampliando as possibilidades de participação social da pessoa (com deficiência).

\section{Contextualização do estudo empírico}

Para a discussão aqui pretendida, trazemos situações de sala de aula registradas a partir de um estudo empírico ${ }^{1}$ realizado em uma escola pública de uma cidade ao sul de Minas Gerais. O aluno focalizado é Nil, com 7 anos e com hipótese diagnóstica de deficiência intelectual.

Segundo informações colhidas pela pesquisadora (uma das autoras deste texto) com a mãe, a gestação e parto de Nil ocorreram sem intercorrências. Em 2015, com quatro anos, ele ingressou na educação infantil e, após um tempo, as professoras relataram falta de atenção, agressividade e agitação. No ano seguinte, ainda na educação infantil, Nil foi encaminhado ao reforço escolar ${ }^{2}$.

Em 2016, Nil ingressou na primeira etapa do ensino fundamental e as queixas de desatenção e agressividade persistiram, fato que levou a escola a encaminhá-lo para avaliação psicopedagógica em uma instituição especial do município, cujo resultado foi hipótese de deficiência intelectual. Diante de tal hipótese, a escola providenciou seu acompanhamento pelo atendimento educacional especializado (AEE) e apoio de uma estagiária de pedagogia para o desenvolvimento de atividades na sala de aula comum. Ao final do ano letivo, nos registros do prontuário escolar constavam que Nil não acompanhava a turma, continuava com o comportamento agressivo, permanecia na maior parte do tempo fora da sala de aula, de modo que não desenvolvia as atividades escolares. Em relação ao processo de escrita, copiava seu nome, diferenciava letras de numerais, mas não grafava todas as letras do alfabeto.

No ano seguinte, em 2017, Nil, em decorrência de mudança domiciliar de sua família, foi matriculado em outra escola. Estava no segundo ano do ensino fundamental e continuou frequentando o AEE, no contraturno; durante os primeiros meses do ano, também teve o apoio de uma estagiária de pedagogia para desenvolver as atividades na sala de aula comum. Nil foi inserido em uma sala com mais 24 alunos. Clara, a professora regente, era bastante experiente e acolhedora. Ela aceitou com entusiasmo a ideia de realização da pesquisa em sua sala e esteve sempre solícita e participativa. Nesta sala, diferente das informações contidas no prontuário das escolas anteriores, Nil participava das atividades com os demais alunos.

Ao longo do ano letivo, a pesquisadora acompanhou o aluno nas aulas e, em parceria com a professora regente, elaborou atividades pedagógicas tendo em vista a escrita como prática social. As atividades foram pensadas de modo a promover processos interativos e potencializar o

\footnotetext{
${ }^{1}$ O estudo compõe a tese de doutoramento de Carvalho (2019) e recebeu a aprovação do comitê de ética em pesquisa, de modo que os nomes dos participantes são fictícios.

${ }^{2}$ No município, o reforço escolar é oferecido no contraturno, pela própria professora regente, como forma de "recuperação" de alunos que apresentam "dificuldades no acompanhamento da turma".
} 
desenvolvimento simbólico dos alunos e não para serem meramente atividades de escrita mecânicas e desprovidas de sentido. Diferentes gêneros de texto foram mobilizados: elaboração de bilhetes para as mães, convite para festa de aniversário, receitas culinárias, lista de ingredientes, entre outros.

Os registros foram realizados por meio de videogravações minuciosamente transcritas (inserindo, além das falas, gestos, expressões e ações dos envolvidos).

Tomamos o caso de Nil como exemplar para refletirmos sobre o processo de escolarização de alunos que recebem o diagnóstico de deficiência intelectual e, mais especificamente, acerca de suas possibilidades de alfabetização.

Com relação ao procedimento analítico, assumimos os princípios da análise microgenética (GÓES, 2000), de modo que apresentamos situações vividas no espaço da sala de aula comum, que nos permitem analisar, nas relações de ensino, indícios dos modos como Nil se relaciona com a escrita e como essa esfera simbólica da linguagem potencializa novas formações psíquicas.

A função das práticas alfabetizadoras e inclusivas: caminhos possíveis na dinâmica escolar

A fim de sustentar nossa compreensão de que o processo de apropriação da linguagem escrita mobiliza e transforma o desenvolvimento de funções psíquicas mediadas, assim como permite à criança (com deficiência) tornar-se partícipe das práticas sociais escolarizadas e alcançar uma outra posição nas relações sociais, a seguir, trazemos situações ocorridas em sala de aula.

Situação 1: A professora e a pesquisadora buscam realizar atividades que envolvam a escrita como prática social. A proposta de atividade é a escrita de um bilhete para as mães que estariam participando de uma reunião na escola. As crianças sentam-se em dupla. Ao lado de Nil, está a estagiária que o acompanha nas atividades.

1. Profa ${ }^{a}$ Clara: Agora vamos escrever o bilhete para a mamãe. (Entrega metade de uma folha de sulfite para os alunos. Tem um coração desenhado na folha.)

2. Nil: (Está em silêncio, observando a professora.)

3. Estagiária Sônia: O que você quer escrever para a sua mãe?

4. Nil: Que gosto dela.

As crianças começam a falar ao mesmo tempo sobre a escrita do bilhete, algumas gritam, outras levantam-se.

5. Profa. Clara: Vamos fazer silêncio, fiquem em suas carteiras, levante o dedo quem quiser falar. Cada um vai falar o que pensa, e depois eu vou escrever no quadro para vocês copiarem.

6. Aluna Ana: Posso escrever o meu diferente?

7. Profa. Clara: Pode mas, primeiro, vamos escrever juntos.

8. Aluno Lucas: Mãe, te amo.

9. Aluno Nil: (levanta o dedo) Mãe, gosto muito de você.

10. Aluna Lara: Obrigado por tudo.

11. Profa. Clara: Quando as mulheres forem escrever a palavra de agradecimento, devem dizer "obrigada" e os meninos dizem "obrigado".

Os alunos continuam a expressar suas ideias e a professora organiza de forma coletiva um único bilhete de agradecimento para as mães e o registra na lousa. Alguns alunos escrevem o próprio texto, de forma diferente, e outros iniciam a cópia da lousa. 
12. Nil: (Continua em seu lugar, com um olhar atento a tudo que está sendo dito, olha para os colegas.)

13. Estagiária Sônia: Vamos, Nil, pega seu lápis e vamos registrar a escrita do bilhete.

14. Profa. Clara: Quando terminarem de escrever o bilhete para a mamãe podem desenhar e colorir bem bonito, pois vou colocá-los em um mural para que no dia da reunião, as mães o leiam e os levem para casa.

15. Nil: (Realiza a cópia da lousa e ilustra seu bilhete.)

Figura 1: Cópia do bilhete para a mãe e desenho feitos por Nil

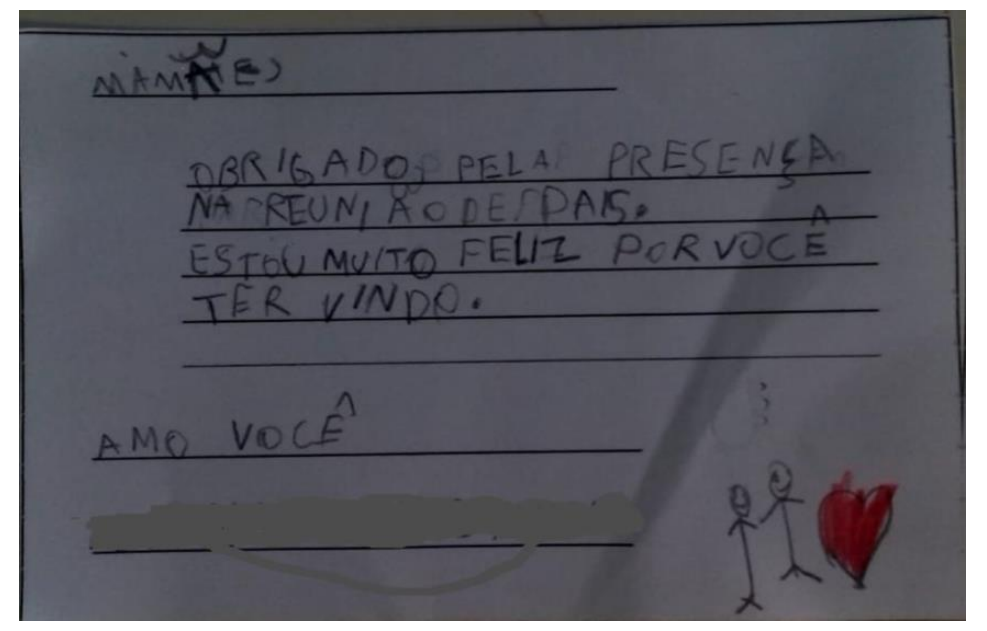

Fonte: a pesquisadora

Nesta situação, vemos a professora mobilizar os alunos para a produção escrita de um bilhete para as mães. As crianças falam ao mesmo tempo, dão suas ideias para a elaboração coletiva do texto. A professora conduz a interação de modo a organizar os momentos de fala e garantir o espaço de participação de cada criança. A escrita vai ganhando sentido em uma produção coletiva. As crianças, envolvendo Nil, encontram na relação de ensino um lugar de voz e a liberdade de produzir um texto coletivo e, também, elaborar um texto individualmente. Assumem o lugar de autoria de um texto que conta com um interlocutor definido.

Chamamos a atenção para o fato de a atividade ser proposta como uma prática social - o bilhete seria exposto em um mural para que as mães pudessem lê-lo no dia da reunião. A questão não é aprender para escrever um gênero, mas produzir uma escrita com funcionalidade. Percebemos a participação de Nil e dos demais alunos inseridos em uma prática social, significativa.

A escritura do bilhete delineia-se como instância de uso efetivo da linguagem articulada à elaboração conjunta e coletiva da escrita pelas crianças e professora. Suscita nos alunos a vontade de dizer por escrito sobre os sentimentos: "mãe te amo"; "gosto de você", "obrigado por tudo". Ressaltamos nesta prática como o sentido da atividade potencializa a relação afetivo-cognitiva no processo de ensino-aprendizagem (VIGOTSKI, 1997). A relação que Nil vai estabelecendo com a linguagem escrita nessa situação de ensino mediada "dá forma" ao significado emocional de sua vivência no meio familiar. Ele mostra, ainda, conhecimento do conteúdo que integra o gênero bilhete que geralmente é produzido no contexto do Dia das Mães.

Nil ainda não escreve com autonomia, mas a proposta da escrita coletiva, mediada pedagogicamente, permitiu que ele participasse da atividade com os demais. $\mathrm{O}$ aluno realizou a 
cópia da lousa mas, neste caso, a cópia não se configura como uma escrita mecânica, desprovida de sentido, pois o conteúdo foi negociado em um coletivo que ele integra, a que ele pertence. A cópia ganha um novo estatuto. Para realizá-la, o aluno precisa dispor de uma organização psíquica: saber que a escrita tem um significado, dominar a grafia das letras, atentar-se para o que está na lousa e realizar a grafia na folha, organizar o texto no espaço dessa folha. As marcas do apagar na folha revelam, ainda, que o processo de revisão textual aconteceu no momento da cópia e contou com a mediação da estagiária. A cópia torna-se, neste caso, um recurso que ancora o processo de elaboração reflexiva da escrita.

Nota-se, pela Figura 1, que a professora orientou a escrita de Nil. Na folha que ela entregou aos alunos, ela faz o traçado das linhas, dispõe as linhas de modo a organizar a estrutura do gênero bilhete. Ao organizar e registrar na lousa a produção coletiva dos alunos, a professora permite que eles percebam como se organiza a escrita de um bilhete e contribui para as suas reflexões sobre os diferentes gêneros textuais. Há na proposta da professora uma intencionalidade pedagógica que é essencial para o domínio da escrita e, neste sentido, ela instrumentaliza os alunos com conhecimentos necessários para esse fim. Podemos dizer que no artefato didático-pedagógico reside a potência dos processos de aprendizagem da escrita.

Por fim, destacamos a inter-relação entre oralidade, desenho e escrita e o modo como estas esferas simbólicas da linguagem se entretecem na prática pedagógica, contribuindo para que os alunos percebam as diferenças entre estes sistemas simbólicos. $\mathrm{Na}$ folha que a professora entregou aos alunos, além das linhas, há o desenho de um coração, uma marca pictográfica, cultural que sugere a ideia de amor, sentimento. Tal marca orienta os alunos acerca das ideias do que escrever no bilhete. Luria (2006) esclarece que a escrita é uma função psíquica que se realiza pela mediação e, deste modo, o registro do coração na folha pode ser tomado como um signo auxiliar que leva a criança a pensar sobre o que escrever para a mãe.

Situação 2: A professora e a pesquisadora estão empenhadas em trabalhar com propostas pedagógicas significativas para as crianças. Desenvolvem atividades envolvendo a escrita, a partir do livro da história infantil $\mathrm{O}$ carteiro chegou ${ }^{3}$. $\mathrm{Na}$ situação, a professora retoma com os alunos uma história extraída do livro na qual um lobo disfarçado de vovó recebe uma carta com cobranças de suas dívidas. Como não gostou do teor da carta, "a falsa vovó" resolve fazer um chá para oferecer ao carteiro. A professora conversa com os alunos sobre o fato.

1. Profa. Clara: O lobo leu a carta e ficou furioso e resolveu fazer um chá para servir ao carteiro. Como será que ia ser este chá?

2. Aluna Giovana: Eu não sei, mas eu não ia tomar.

3. Aluna Maria: Acho que tinha veneno.

4. Profa. Clara: O que mais vocês acham que tinha neste chá?

5. Aluno Nil: Remédio que dorme.

6. Profa. Clara: Sim, pode ser um sonífero.

7. Aluno Nil: O que é isto?

8. Profa ${ }^{\text {a }}$ Clara: O nome do remédio, Nil, que você sugeriu para a pessoa dormir.

$\mathrm{Na}$ sequência, a professora solicita aos alunos para pensarem em ingredientes para o chá que o lobo faria ao carteiro.

\footnotetext{
${ }^{3}$ De Janet \& Allan Ahlberg, publicado pela Companhia das Letrinhas, 2007. O livro apresenta diversos contos que trazem um carteiro como personagem principal e que realiza seu trabalho entregando cartas para destinatários que são personagens das histórias dos contos infantis tradicionais.
} 
9. Profa . Clara: Agora imaginem que cada um de vocês seja o lobo da história e devem inventar um chá para servir ao carteiro. O que vocês precisam para fazer o chá?

10. Aluna Giovana: Água.

11. Prof ${ }^{a}$. Clara: Primeiro vamos nos organizar, colocando todos os ingredientes que vocês precisam para preparar a receita do chá para o carteiro. Façam uma lista, uma palavra embaixo da outra.

12. Pesquisadora: Como você vai escrever a palavra água?

13. Aluno Nil: Começa com "a". (Escreve a letra a em sua folha.)

14. Pesquisadora: E agora?

15. Nil: (Mexe no caderno, olha para a pesquisadora.)

16. Pesquisadora: Depois da letra "a", o que você vai escrever?

17. Aluno Nil: "u".

18. Pesquisadora: Antes da letra "u", que letra é?

19. Aluno Nil: " $n$ ", " $r$ ".

20. Pesquisadora: Calma, tem que repetir a palavra, qual som você ouve? Não é assim falar qualquer letra.

21. Aluno Nil: (Olha para a pesquisadora, leva a mão direita ao queixo, em gesto pensativo.)

22. Pesquisadora: Água.

23. Aluno Nil: "g" "u".

24. Pesquisadora: Escreve aí, depois da sílaba a.

25. Aluno Nil: (Escreve gu).

26. Pesquisadora: E agora, qual é a última letra?

27. Nil: Água "na".

28. Pesquisadora: Não, qual é a última letra que você fala da palavra?

29. Aluno Nil: "a" de novo (Ele escreve, levanta a cabeça e olha com sorriso.)

30. Pesquisadora: Você vai fazer um chá de que? Você já tomou chá de que?

31. Aluno Nil: De flor.

32. Pesquisadora: De flor? Que flor é essa?

33. Aluno Nil: Flor verdinha.

34. Pesquisadora: É hortelã?

35. Aluno Nil: Ah, é sim! Minha mãe faz pra gente (sorrindo).

36. Pesquisadora: Vamos pensar! Você já tomou esse chá, ele é gostoso, cheiroso, como será que se escreve?

37. Aluno Nil: "o".

38. Pesquisadora: Isso! Só que antes da letra "o", tem a letra "h"

39. Aluno Nil: (escreve a letra "h").

40. Pesquisadora: E agora que letra falta para formar o som do hor? (reforçando a entonação da letra " $r$ ")

41. Aluno Nil: "d".

42. Pesquisadora: Será?

43. Aluno Nil: "r" "e" (escreve).

44. Pesquisadora: E agora, como se escreve a sílaba "te"?

45. Aluno Nil: É “e”.

46. Pesquisadora: Sim, mas antes da letra "e" tem...

47. Aluno Nil: (Olha para a pesquisadora, levanta a sobrancelha.) É " $\mathrm{t}$ " “e” (escreve).

48. Pesquisadora: Horte?

49. Aluno Nil: "lo". 
50. Pesquisadora: Hortelã (com entonação em cada uma das sílabas).

51. Aluno Nil: "le".

52. Pesquisadora: Não é hortele.

53. Aluno Nil: É “a”.

54. Pesquisadora: "la" e tem acento til no "â", para formar o som do "lâ".

55. Aluno Nil: "lẫ" (escreve)

Enquanto isso, os demais alunos também estão sugerindo e escrevendo a lista com os ingredientes para o chá.

56. Profá. Clara: Chá de hortelã, de camomila é muito bom, só que o lobo é um lobo bom ou um lobo mau?

57. Alunos: Mau.

58. Profa . Clara: Será que eu vou preparar um chá gostoso ou um chá ruim?

59. Aluna Giovana: Eu vou colocar pimenta no meu chá.

60. Pesquisadora: E você, Nil, o que poderia colocar no seu chá para o chá não ficar muito bom?

61. Aluno Nil: Pimenta.

62. Pesquisadora: Pimenta, sua colega já falou, pense em alguma coisa diferente.

63. Profa . Clara: Tem um monte de gente com ideias legais, mas tem que escrever.

64. Pesquisadora: Você quer escrever sua ideia?

65. Aluno Nil: Quero, vou colocar gasolina.

66. Pesquisadora: Você vai escrever gasolina, vamos lá.

(Nil, com o auxílio da pesquisadora, escreve a palavra gasolina.)

67. Pesquisadora: Isso Nil, vamos ver o que falta para terminar.

68. Nil: O hortelã é para disfarçar e enganar carteiro.

Destacamos, nesta situação de ensino-aprendizagem, o movimento da professora e da pesquisadora na direção de buscar caminhos para promover uma prática pedagógica direcionada às demandas educacionais orientadas para a dimensão prospectiva do desenvolvimento. A professora acolhe as contribuições dos alunos na reelaboração da história coletiva e, por meio de questionamentos, os mobiliza a participarem do processo criativo. É importante considerar que a relação dialógica estabelecida gira em torno de uma história lida pela professora aos alunos. Muitos estudos já argumentaram a favor da funcionalidade da leitura e da escrita; crianças aprendem a ler e a escrever lendo e escrevendo imersas em contextos diversificados e significativos. Alfabetizar não se reduz ao domínio de um código, mas implica práticas de leitura e de escrita situadas e referenciadas socialmente, que contemplem a dimensão simbólica, pragmática, lúdica e dialógica da linguagem (SMOLKA, 2019). As histórias infantis, em geral, aguçam a curiosidade e a vontade da criança para a leitura, mobilizam funções psíquicas e fomentam o processo criativo. "O que será que tem no chá?”, pergunta a professora Clara, convocando as crianças para a imaginação: “veneno, remédio que dorme". Nas relações entre alunos e professora, conceitos vão sendo alçados no trabalho interfuncional. "O que é sonífero?", indaga Nil.

O trabalho pedagógico envolvendo o desenvolvimento da linguagem escrita é complexo, na medida em que demanda dos professores a elaboração de atividades que valorizem a escrita como uma prática social, significativa, mas sem perder de vista questões formais, como se escreve, que grafemas usar para compor as palavras, a organização do texto a depender do gênero textual. $\mathrm{Na}$ situação, professora e pesquisadora valem-se de estratégias para assegurar a aprendizagem da escrita: provocam o jogo simbólico, questionam sobre o enredo e o desfecho da história, interrogam as hipóteses de escrita do aluno, atribuem significado e dinamizam o processo de 
elaboração conceitual, fornecem pistas orais subsidiando a relação fonema-grafema. O trabalho conjunto entre professora e pesquisadora permitiu o apoio necessário para sustentar a relação efetiva do aluno, com hipótese diagnóstica de deficiência intelectual, com os vários aspectos envolvidos na elaboração da escrita. Nil ocupa o lugar de aluno nas práticas de alfabetização: ouve explicações, expõe ideias, constrói hipóteses, registra, trabalha individual e coletivamente... Os seus modos de participar expressam a sua motivação, interesse, envolvimento na atividade de leitura e escrita.

Na situação, a pesquisadora questiona "Você vai fazer um chá de que? Você já tomou chá de que?". Nil precisa pensar, criar, elaborar - "chá de flor, flor verdinha" -, nomeado pela pesquisadora como chã de hortelã. Atenção, imaginação, formação conceitual: funções psíquicas mediadas que se entretecem no processo de elaboração da escrita. A situação social de desenvolvimento na qual Nil está inserido torna-se fonte de produção de novas configurações interfuncionais, potencializando processos de aprendizagem. A condição de deficiência intelectual de Nil é redimensionada nas situações de ensino mediadas. Em outros termos, podemos observar como o aluno vivencia a relação com a escrita e como essa vivência torna-se situação social de desenvolvimento.

Ademais, no trabalho com a linguagem escrita, Nil mobiliza elementos do que foi vivido por ele nas relações familiares, como na produção coletiva da lista dos ingredientes para o chá: "minha mãe faz pra gente". Lembrança carregada de afeto e sentido para Nil. A vivência diz respeito ao modo como os sujeitos, nas relações, atribuem sentidos às suas experiências. A vivência é mediada pela linguagem - aquilo que significa (VIGOTSKI, 2018).

Ao pensar no que quer escrever, Nil movimenta sua imaginação, seu pensamento - "vou colocar gasolina, o hortelã é para disfarçar e enganar o carteiro". Vamos percebendo que a escrita, como uma nova formação, mobiliza o trabalho com a imaginação e ancora o processo de conceitualização, complexifica a organização dos sistemas funcionais.

A análise dessa situação nos permite compreender a configuração de uma prática pedagógica alfabetizadora e inclusiva, potencializadora do trabalho com a linguagem escrita. Nil participa com interesse da atividade, tanto dos momentos coletivos - quando a professora solicita que os alunos deem sugestões -, como dos momentos de produção de texto, que faz na parceria com a pesquisadora. $\mathrm{O}$ aluno com hipótese diagnóstica de deficiência intelectual, em processo de alfabetização, participa efetivamente da atividade curricular.

Por fim, neste processo, observamos como as funções psíquicas mediadas se entrelaçam e se complexificam, de modo que a linguagem escrita produz novas formas de pensamento e ancora diversos modos de interação entre Nil, seus colegas, a professora e a pesquisadora. Como já mencionamos, a linguagem escrita, em sua historicidade, permite a pessoa ampliar a participação no universo simbólico e acessar os conhecimentos elaborados na cultura humana (VIGOTSKI, 1995; SAVIANI, 2013). Argumentamos que essa é uma nova formação que complexifica a organização das funções psíquicas mediadas: vontade, imaginação, elaboração conceitual. Vigotski (1995, p. 34) nos diz que "[...] a cultura origina formas especiais de conduta, modifica a atividade das funções psíquicas, funda novos níveis no sistema de comportamento humano em desenvolvimento".

\section{CONSIDERAÇÕES FINAIS}

A fim de suplantar a ideia, historicamente constituída, de educação especial como caridade pública e efetivar plenamente o direito à educação desse alunado, é preciso garantir a apropriação 
dos conhecimentos - filosóficos, artísticos, científicos - que a humanidade desenvolveu e que fomenta o currículo escolar. A alfabetização é base para esse processo que integra o desenvolvimento cultural dos alunos (com deficiência) e garante a condição de pertencimento à sociedade letrada.

Com base na perspectiva histórico-cultural, concebemos a linguagem escrita como prática social que se transforma em nova formação psíquica, incidindo nas conexões funcionais. Em outros termos, a apropriação da escrita provoca mudanças na organização das funções psíquicas mediadas e afeta a estrutura da personalidade na sua integralidade; amplia o desenvolvimento histórico da consciência; produz formas elaboradas de pensamento e complexifica os modos de (inter)ação, possibilitando a criança atingir outra posição na relação estabelecida com o meio social.

A partir da análise de situações escolares envolvendo um aluno com hipótese diagnóstica de deficiência intelectual, argumentamos que as práticas alfabetizadoras incidem na situação social de desenvolvimento possibilitando a constituição de novas formações psíquicas. Com isso, chamamos a atenção para propostas de ensino da linguagem escrita que priorizem as crianças e suas vivências e que considerem os modos heterogêneos de aprender, os vários ritmos e caminhos de desenvolvimento, as múltiplas relações com a língua(gem), as situações enunciativas que engloba os aspectos formais e a produção de sentidos. Dessa forma, o objetivo do trabalho pedagógico deve consistir em subsidiar práticas que atendam as singularidades e as demandas específicas de cada estudante, de modo a veicular conhecimento nas relações afetivas-cognitivas estabelecidas no processo de escolarização.

Alfabetizar faz-se, portanto, como um gesto/ato político-pedagógico, cujo propósito é intervir no desenvolvimento humano e contribuir no processo de transformação social.

\section{REFERÊNCIAS}

BUENO, José Geraldo Silveira.; MELETTI, Silvia Márcia Ferreira. O impacto das políticas públicas de escolarização de alunos com deficiência: uma análise de indicadores sociais no Brasil. Linhas Críticas. Brasília, DF, v. 17, n. 33, p. 367-383, 2011. Disponível em https://periodicos.unb.br/index.php/linhascriticas/article/view/3739. Acesso em 12 jan. 2021.

CARVALHO, Claudia Adriana Silva de Mello. O ensino da escrita na perspectiva do letramento social: análise do caso de um aluno com hipótese de deficiência intelectual. 150 f. Tese, Doutorado em Educação, Programa de Pós-Graduação em Educação da Universidade São Francisco, Itatiba, 2019.

CARVALHO, Maria de Fátima. O aluno com deficiência intelectual na escola: ensino, aprendizagem e desenvolvimento humano. In: MELETTI, Silvia Márcia Ferreira; KASSAR, Mônica de Carvalho Magalhães. Escolarização de alunos com deficiências: desafios e possibilidades. Campinas: Mercado de Letras, 2013. p. 203-241.

CASTRO, Vanessa Dias Bueno de; DALL'ACQUA, Maria Júlia Canazza. Matrículas de alunos público-alvo da educação especial: dados dos censos escolares entre 2008 e 2012. In: Encontro da Associação Brasileira de Pesquisadores em Educação Especial, 2013, Londrina. Anais... Londrina: [s. n.], 2013. $\quad$ Disponível em http://www.uel.br/eventos/congressomultidisciplinar/pages/arquivos/anais/2013/AT022013/AT02-021.pdf. Acesso em 2 out. 2016. p. 1173-1181.

DAINEZ, Débora; SMOLKA, Ana Luiza Bustamante. A função social da escola em discussão, sob a perspectiva da educação inclusiva. Educação e Pesquisa, São Paulo, v. 45, p. 1-18, 2019. 


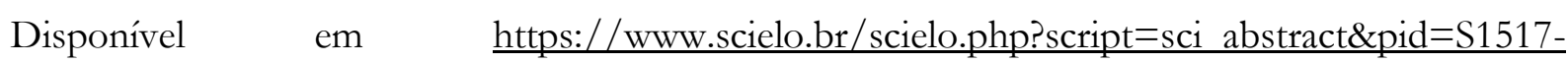
97022019000100401\&lng=en\&nrm=iso\&tlng=pt. Acesso em 13 jan. 2021.

FREITAS, Ana Paula de; PINTO, Glaucia Uliana; MONTEIRO, Maria Inês Bacellar. Elaboração conceitual de alunos com deficiência intelectual: possibilidades em contextos formativos. Práxis Educacional, v. 15, p. 493-516, 2019. Disponível em https://periodicos2.uesb.br/index.php/praxis/article/view/4684. Acesso em 17 fev. 2021.

GÓES, Maria Cecília Rafael de. A abordagem microgenética na matriz histórico-cultural: uma perspectiva para o estudo da constituição da subjetividade. Cadernos CEDES, Campinas, São Paulo, v. 20, p. 9-25, 2000.

LURIA, Alexander Romanovich. O desenvolvimento da escrita na criança. In.: VIGOTSKI, Lev Semionovich; LURIA, Alexander Romanovich; LEONTIEV, Alex N. Linguagem, desenvolvimento e aprendizagem. Trad. Maria da Pena Villalobos. 10. ed. São Paulo: Ícone, 2006, p. 143-189.

MARSIGLIA, Ana Carolina Galvão; SAVIANI, Dermeval. Prática pedagógica alfabetizadora à luz da psicologia histórico-cultural e da pedagogia histórico-crítica. Psicologia em Estudo, Maringá, Paraná, v. 22, n. 1, p. 3-13, 2017.

PADILHA, Anna Maria Lunardi; OLIVEIRA, Ivone Martins de. Educação para todos: as muitas faces da inclusão escolar. Campinas: Papirus, 2013.

PLETSCH, Márcia Denise. Educação especial e inclusão escolar: políticas, práticas curriculares e processos de ensino e aprendizagem. Poiésis Pedagógica, Catalão, Goiás, v. 12, n. 1, p. 7-26, 2014. Disponível em http://www.revistas.ufg.br/poiesis/article/view/31204/16802. Acesso em 13 jan. 2021.

SAVIANI, Dermeval. Escola e democracia. 41. ed., Campinas, São Paulo: Autores Associados, 2009. SAVIANI, Dermeval. Pedagogia histórico-crítica: primeiras aproximações. 11. ed., Campinas, São Paulo: Autores Associados, 2013.

SMOLKA, Ana Luiza Bustamante. Relações de ensino e desenvolvimento humano: reflexões sobre as (trans)formações na atividade de (ensinar a) ler e escrever. Revista Brasileira de Alfabetização, v. 1, p. $12-28,2019.2$ Disponível em https://revistaabalf.com.br/index.html/index.php/rabalf/article/view/314. Acesso em $17 \mathrm{fev}$. 2021.

SOUZA, Flavia Faissal. Indagações e contradições sobre a ocupação do lugar de aluno com deficiência intelectual no cotidiano de uma escola de ensino fundamental pública de periferia. Horizontes, Itatiba, São Paulo, v. 36, n. 3, p. 74-85, 2018. Disponível em https://revistahorizontes.usf.edu.br/horizontes/article/view/703. Acesso em 13 jan. 2021.

VIGOTSKI, Lev Semionovich. 7 Aulas de L.S. Vigotski sobre os fundamentos da pedologia. PRESTES, Zoia; TUNES, Elizabeth (orgs. e trad.). 2. ed. Rio de Janeiro: E-Papers, 2018.

VYGOTSKI, Lev Semionovich. Problemas del desarrollo de la psique. Obras Escogidas, v. III. Madrid: Visor Distribuiciones S.A., 1995.

VYGOTSKI, Lev Semionovich. Psicología infantil (incluye Paidología del adolescente, problemas de la psicología infantil). Obras Escogidas, v. IV, Madrid: Visor Distribuiciones S.A., 1996.

VYGOTSKI, Lev Semionovich. Fundamentos de defectologia. Obras Escogidas, v. V, Madrid: Visor Distribuiciones S.A., 1997. 


\section{Informações das autoras}

Ana Paula de Freitas

Programa de Pós-Graduação em Educação da Universidade São Francisco, Campus Itatiba.

E-mail: freitas.apde@gmail.com

ORCID: https://orcid.org/0000-0003-1570-1996

Link Lattes: http://lattes.cnpq.br/8758283696346416

Débora Dainez

Departamento de Ciências Humanas e Educação e Programa de Pós-Graduação em Educação da Universidade Federal de São Carlos, Campus Sorocaba.

E-mail: ddainez@yahoo.com.br

ORCID: https://orcid.org/0000-0002-8223-098X

Link Lattes: http://lattes.cnpq.br/46718684444231806

Claudia Adriana Silva de Mello Carvalho

Secretaria de Educação do Município de Itajubá

E-mail: cstussi@hotmail.com

ORCID: https://orcid.org/0000-0003-2170-4042

Link Lattes: http://lattes.cnpq.br/5345034801840119 